\title{
Molecular Detection for Nosocomial Pseudomonas aeruginosa and its Relationship with multidrug Resistance, Isolated from Hospitals Environment
}

\author{
Wathiq Abbas Hatite Al-Daraghi' ${ }^{1}$, Mohammed Sattar Abdulkadhim Al-Badrwi ${ }^{2}$ \\ ${ }^{1}$ Institute of Genetic Engineering and Biotechnology for Postgraduate Studies, University of Baghdad, Iraq.
}

\begin{abstract}
Pseudomonas aeruginosa is an important pathogen in hospitalized patient's causative to their morbidity and mortality due to its multiple resistance mechanisms. Therefore, as a therapeutic option becomes restricted, the search for a new agent is a priority. So Pseudomonas aeruginosa is an extremely versatile Gram-negative bacterium capable of thriving in a broad spectrum of environments, and this performs main problems to workers in the field of doctors and nurses. One hundred and fifty samples were collected from different sources from Al-Kut hospitals, divided into two main groups: clinical (80)samples and (70) samples as a Nosocomial, collected from October to the December of the year 2018. All of these samples were cultured by specific and differential media, Forty (40) isolates of P.aeruginosa bacteria were identified by using microscopic examination, biochemical tests. The identification of (40) isolates of P.aeruginosa confirmed VITEK-2 system. The antibiotic sensitivity test recognized for all bacterial isolates and the results showed high sensitivity to amikacin, gentamicin, ciprofloxacin and Chloramphenicol, and high resistant to oxacillin and Cefoxitin. A molecular diagnosis is recognized by conventional PCR technique to detect the specified gene amplification products of the blaOXA-1 gene for Pseudomonas aeruginosa.
\end{abstract}

Keywords: Hospitals ; Pseudomonas aeruginosa ; multidrug Resistance.

\section{Introduction}

Pseudomonas aeruginosa is a Gram-negative bacillus, straight or slightly curved rods, non-spore forming, capsulate; it is usually motile by one polar flagellum (monotrichous), measuring about $1-5 \mu \mathrm{m}$ long and $0.5-1.0 \mu \mathrm{m}$ wide. It occurs as single bacteria, in pairs and occasionally in short chains possess mucous layer due to material alginate slime layer as well as, multi-layers of extracellular polysaccharide ${ }^{(1)}$. The bacterium is ubiquitous in soil, a variety of aqueous solutions, including disinfectants, soaps, eye drops, as well as sinks and respiratory equipment, some strains hemolysis blood completely ( $\beta$-hemolysis) by producing hemolysis toxin. $P$. aeruginosa forms smooth round colonies and irregular edge with a fluorescent greenish to yellow pigment pyoverdine. It also produces the nonfluorescent bluish pigment pyocyanin, which diffuses into the agar. Many types of media may be used for selective isolation of $P$. aeruginosa like cetrimide agar which promotes pyocyanin, pyoverdine, and pyoyrubin red colour and pyomelanin black colour production ${ }^{(2)}$.
Pseudomonas aeruginosa is one of the most important secondaries of the hospital-acquired infection in burnt patients ${ }^{(3)}$, and it is leading to the nosocomial pathogen, causing infections that usually accrue late during hospital stay ${ }^{(4)}$.P. aeruginosa groups have a tendency to form biofilms, which are compound bacterial groups that stick to a variety of surfaces together with plastics, medical transplant materials, and tissue. They are very difficult to destroy $(5,6) P$. aeruginosa produces the resource of virulence factors, as well as pili, flagella exopolysaccharides, proteases, elastase, lipases, iron chelators and a variety of various toxins, including pyocyanin, chemical compound, exotoxin $\mathrm{A}$, and the Type III Secretion System (T3SS) toxins ExoS, ExoT, ExoU, and ExoY ${ }^{(7)}$.

\section{Materials and Method}

\section{Specimens' Collection:}

Through the period prolonged from October to December of the year 2018, One hundred and fifty specimens were collected from some hospitals including 
80 clinical samples from hospitalized patients and

70 samples from Nosocomial sources. The clinical samples included four main clinical sources: Urine samples, exudate samples from wounds of the burn units patients, stool samples, Sputum samples from Cystic Fibrosis(CF) patients and Ear Swabs. The nosocomial samples included many hospital nosocomial sources: ICU, Operations Hall, Birth Hall, burning gowns, Devices and medical equipment, hand wash and hospital bed rooms.

\section{Bacterial Isolation}

Both of the clinical and Nosocomial samples were cultured on MacConkey agar, Nutrient agar, Blood agar, and Cetrimide agar, incubated for 24 hours at $37^{\circ} \mathrm{C}$. this isolates may belong to Pseudomonas aeruginosa growth on Cetrimide agar for characterization of Pseudomonas aeruginosa such as blue-greenish colour, mucoid colony, smooth in shape, and have a fruity odour. colonies were picked and re-cultured on another MacConkey agar plates in order to be appeared as pale greenish and lactose non-fermenter colonies, while on Blood agar they appeared as large, opaque irregular colonies with butyrous consistency(shiny) give fruity odour and $B$-hemolytic colonies. and on Nutrient agar appeared as yellowish green, smooth in shape with flat edges and elevated center. Further identification tests included the morphological characteristics and biochemical tests were carried out depending on Forbes et al. ${ }^{\left({ }^{(8)}\right.}$.

\section{Bacterial Identification:}

Colonial morphology on MacConkey agar, Nutrient agar, blood agar, and Cetrimide agar was depended initially to identify bacterial isolates, colony shape, texture, colour and edges were examined. In addition to macroscopic characteristics; microscopic examination of a gram-stained slide was examined under a light microscope with special regard towards cell shape and arrangement. Biochemical tests and VITEK 2 system were depended to complete the identification of $P$. aeruginosa isolates.

\section{PCR amplification:}

DNA template of all bacterial isolates was prepared by boiling method $\left(30 \mathrm{~min}\right.$ in $\left.100^{\circ} \mathrm{C}\right)$. The DNA of isolates was targeted only for the blaoxa-1 gene using the primer (Z. Tavajjohi, et al Iran ${ }^{(9)}$ listed in Table 1. A reaction mixture $(25 \mu \mathrm{l})$ contained $2 \mu \mathrm{l}$ of DNA, $1 \mu \mathrm{l}$ of each primer, $12.5 \mu \mathrm{l}$ of Master Mix 2X (Z.Tavajjohi, et al ., 2011), and $8.5 \mu \mathrm{l}$ of nuclease free water. The experiment was sustained according to the following program: initial denaturation at $95^{\circ} \mathrm{C}$ for 5 minutes, followed by 30 cycles at $95^{\circ} \mathrm{C}$ for $30 \mathrm{Sec}$, $55^{\circ} \mathrm{C}$ for 30 Sec. , $72^{\circ} \mathrm{C}$ for $30 \mathrm{Sec}$. and a final extension at $72^{\circ} \mathrm{C}$ for 7 minutes. The PCR products were analyzed using gel electrophoresis ( $1 \%$ agarose) and stained with safe dye and visualized by Gel Doc apparatus (BioRad, USA) (Table 2).

Table (1): Primers used in this study.

\begin{tabular}{|l|l|l|l|l|}
\hline \multirow{2}{*}{ Gene } & \multicolumn{2}{|l|}{ Primer Sequence } & $\begin{array}{l}\text { Product size } \\
\text { (bp) }\end{array}$ & References \\
\hline \multirow{2}{*}{ bla OXA-1 } & F & 5`-AGCCGTTAAAATTAAGCCC-3` & \multirow{2}{*}{908} & $\begin{array}{l}\text { Z.Tavajjohi, et al } \\
\text {., 2011 }\end{array}$ \\
\cline { 2 - 5 } & R & 5`-CTTGATTGAAGGGTTGGGCG-3` & & \\
\hline
\end{tabular}

Table (2): Condition of PCR Reaction for the gene bla OXA-1 of Pseudomonas aeruginosa.

\begin{tabular}{|l|l|l|l|}
\hline Steps & Temperature & Time & Number of Cycle \\
\hline $\begin{array}{l}\text { Initial } \\
\text { Denaturation }\end{array}$ & $95^{\circ} \mathrm{C}$ & 5 min. & \multirow{2}{*}{1} \\
\cline { 1 - 2 } Denaturation & $95^{\circ} \mathrm{C}$ & 30 Sec. & \multirow{2}{*}{30} \\
\cline { 1 - 2 } Annealing & $55^{\circ} \mathrm{C}$ & 30 Sec. & \\
\cline { 1 - 3 } Extension & $72^{\circ} \mathrm{C}$ & 30 Sec. & 1 \\
\hline Final extension & $72^{\circ} \mathrm{C}$ & 7 min. & 1 \\
\hline Hold & $10^{\circ} \mathrm{C}$ & $10 \mathrm{~min}$. & 1 \\
\hline
\end{tabular}




\section{Results and Discussion}

Isolation and Identification of Pseudomonas aeruginosa:

Out of One hundred and fifty samples, clinical and Nosocomial specimens were analyzed for the presence of Pseudomonas aeruginosa, the results of bacterial isolation and identification revealed the detection of forty (40) isolates of Pseudomonas aeruginosa.

\section{Biochemical Tests:}

Some biochemical tests were performed for more validation. showed 40 isolates of P.aeruginosa provided by some biochemical tests, results showed positive results for oxidase test, catalase test, motility test, , and production of $B$-hemolysis while (40) isolations negative results to citrate utilization tests, indole production and urease production tests negative to Gram's stain and capable of growing on cetrimide agar as blue greenish colonies (at $37^{\circ} \mathrm{C}$ for $24 \mathrm{hrs}$.). (figure 1, table 3).

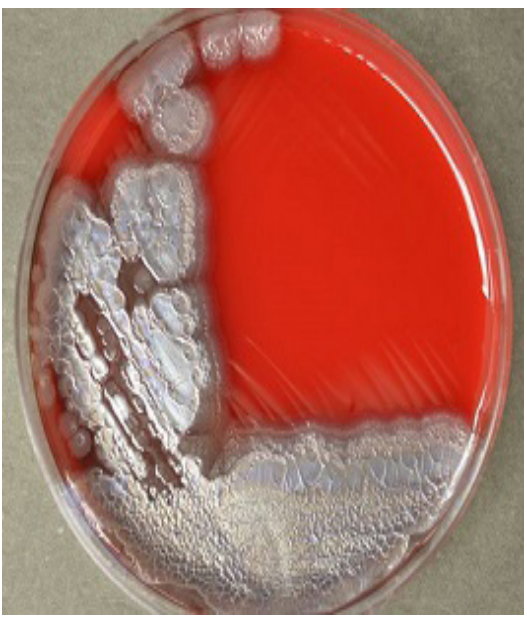

A



$\mathrm{B}$
$\mathrm{C}$

Figure (1): Pseudomonas aeruginosa colonies on (A) Blood agar $r$ and (B) Cetrimide agar and (C)Nutrient agar, after 24 hours of incubation at $37^{\circ} \mathrm{C}$.

Table (3): The biochemical tests of Pseudomonas aeruginosa

\begin{tabular}{|l|l|}
\hline Biochemical test & Result \\
\hline Gram stain & G- rods \\
\hline Kligler's iron agar & K/K \\
\hline Growth at $42^{\circ} \mathrm{C}$ & + \\
\hline Motility & + \\
\hline Oxidase production & + \\
\hline Catalase production & + \\
\hline Hemolysis(ß-hemolysis) & + \\
\hline Indole production & - \\
\hline Urease production & - \\
\hline Methyl-red & - \\
\hline Voges-Proskauer & - \\
\hline Lactose fermentation & - \\
\hline Simmon's citrate & + \\
\hline
\end{tabular}

(+) Positive result, (-) Negative result 
$P$. aeruginosa has a wide growth temperature range, optimum growth at $37^{\circ} \mathrm{C}$. Slower growth rates are seen at $4^{\circ} \mathrm{C}$. P. aeruginosa is distinguishable from other clinically Pseudomonas spp. by its capability for growth at $42^{\circ} \mathrm{C}$. They also grow well at $\mathrm{pH}$ range 6.6-7.0. It was tolerant of a wide variety of physical conditions, including temperature and $\mathrm{pH}$. Also, it was resistant to high concentrations of salts and dyes. It is typically given a positive result to the oxidase test and catalase. It does not ferment carbohydrates, but many strains oxidize glucose ${ }^{(10)}$. The identification was performed with the automated VITEK-2 system using the GN-ID cards which contains 64 biochemical tests, from (40) isolate of $P$. aeruginosa (40) positive result of the $P$. aeruginosa demonstrated.

\section{Distribution of $P$. aeruginosa according to Type of Specimens :}

A percentage of about $50 \%$ (40) isolates belonged to P.aeruginosa from total 80 isolates, $28(70 \%)$ isolates were positive to clinical $P$. aeruginosa and $12(30 \%)$ isolates were positive for Nosocomial sources. The percentage of the positive results from burns, ears and wounds were $5 \%, 27.5 \%$ and $12.5 \%$ respectively (table 4).

Table (4): Distribution of Pseudomonas aeruginosa isolates in Nosocomial samples

\begin{tabular}{|l|l|}
\hline Site of samples & $\begin{array}{l}\text { Numbers of sample and } \\
\text { Percentage }\end{array}$ \\
\hline ICU & $2(5 \%)$ \\
\hline Operations Hall & $4(10 \%)$ \\
\hline Birth Hall & $2(5 \%)$ \\
\hline Burn Hall & $2(5 \%)$ \\
\hline $\begin{array}{l}\text { Devices and medical } \\
\text { equipment }\end{array}$ & $2(5 \%)$ \\
\hline Total & $12(30 \%)$ \\
\hline
\end{tabular}

The low percentage was found in burn specimens which accomplished 5\%. Results obtained reported that the highest percentage of Pseudomonas aeruginosa from ear swab (27.5\%). In comparison with Nosocomial isolates of Pseudomonas aeruginosa the highest percentage isolation of Operations Hall (4\%) where are the isolates reported low present in burn hall, birth hall and Devices and medical equipment (2\%) in comparison with clinical findings.

$P$. aeruginosa is well-adapted to the respiratory tract environment, especially in patients with the chronic obstructive bronchopulmonary disease, who are hospitalized in intensive care units or immunocompromised, (11). Pseudomonas aeruginosa is very hard to kill because of its ability to build resistance to many cleaners and medicines. Pseudomonas aeruginosa is accountable for $16 \%$ of healthcare facility respiratory disease cases, $12 \%$ of hospital-acquired UTI, $8 \%$ of surgical wound contaminations, and $10 \%$ of blood stream infections. ${ }^{(12)}$. Vandeale et al. (2005) ${ }^{(13)}$ studied the epidemiology of $P$. aeruginosa in cystic fibrosis rehabilitation centre, sixty-seven isolates of $P$. aeruginosa were isolated from patient's sputum, the infection by patient-to-patient-transmission could have happened in the past, the risk of patient-to-patient transmission during the study period (63day) was relatively $(10 \%)$ and the risk of persisting colonization with a newly acquired strain during the study period was $(4 \%)$.

\section{Antibiotics Resistance in $P$. aeruginosa}

In the present study the in vitro antibiotic sensitivity test of isolated

P. aeruginosa strains examined revelled Amikacin and Gentamicin to be the most effective antibiotic followed by Ceftriaxone, Ciprofloxacin \& Cefotaximeclavulanic acid in decreasing order as reported in the table(5).

Table (5): Antibiotic resistance and sensitivity of Pseudomonas aeruginosa to antibiotics

\begin{tabular}{|l|l|l|l|l|}
\hline \multirow{2}{*}{$\begin{array}{l}\text { Antimicrobial } \\
\text { Agent }\end{array}$} & \multicolumn{3}{|l}{$\begin{array}{l}\text { Pseudomonas aeruginosa } \\
\text { isolates })\end{array}$} \\
\cline { 2 - 5 } & S & R \\
\cline { 2 - 5 } & No. & $\%$ & No. & $\%$ \\
\hline Amikacin(AK) & 40 & $100 \%$ & 0 & $0 \%$ \\
\hline Gentamicin(GN) & 40 & $100 \%$ & 0 & $0 \%$ \\
\hline $\begin{array}{l}\text { Cefotaxime- } \\
\text { clavulanic acid } \\
\text { (CEC) }\end{array}$ & 30 & $75 \%$ & 10 & $25 \%$ \\
\hline Aztreonam(AT) & 20 & $50 \%$ & 20 & $50 \%$ \\
\hline Cefoxitin(CX) & 3 & $7.5 \%$ & 37 & $92.5 \%$ \\
\hline Ceftriaxone(CTR) & 35 & $87.5 \%$ & 5 & $12.5 \%$ \\
\hline Oxacillin(OX) & 0 & $0 \%$ & 40 & $100 \%$ \\
\hline Ciprofloxacin(CIP) & 35 & $87.5 \%$ & 5 & $12.5 \%$ \\
\hline
\end{tabular}


Antibiotic sensitivity testing is an essential tool for treatment. $P$. aeruginosa is considered as one of UTI infection, burn, CF , otitis ear and wound infection is resistant to a range of antibiotics due to the permeability barrier provided by its outer membrane for hydrophilic substances, although using sometimes surfactant as a permeabilizing agent to enhance the interaction of hydrophilic material with the hydrophobic cell wall did not enhance the antibacterial activity of some agent against $P$. aeruginosa ${ }^{(14)}$. Malla et al ${ }^{(15)}$ reported that $P$. aeruginosa were susceptible $100 \%$ to Amikacin and Gentamycin which are similar to our study.

Another study by V. Saegeman1a et al,. (2010)(16) stated that $P$. aeruginosa had shown high sensitivity to a $\beta$-lactamase antibiotic with $100 \%$ for Amikacin(AK), 95 $\%$ to Gentamicin(GN) and $87.5 \%$ to Ciprofloxacin(CIP). Osazuwa et al., $(2011)^{(17)}$ in Nigeria recorded $100 \%$ resistance for both oxacillin and Cefoxitin(CX). These results agree with the percentages in this study.

Resistance to some antibiotics such as cefotaxime, neomycin and kanamycin showed an increase in comparison with previous studies, this might be due to the variation in the usage of antibiotics ${ }^{(18)}$.

\section{Genomic DNA Extraction:}

Using a genomic DNA purification kit (Promega), Genomic DNA was extracted from Pseudomonas aeruginosa isolates. Extraction genomic DNA from 40 isolates that were confirmed as bands by gel electrophoresis. The DNA concentration and purity were measured by Nanodrop spectrophotometer, all the isolates had DNA concentration between $(50-100 \mathrm{ng} / \mu \mathrm{l})$ and purity of the DNA.

\section{Molecular Detection of Pseudomonas aeruginosa} by bla oxa1 like gene:

The result of PCR analysis concerning of the found the blaoxa 1 , showed that studies $P$. aeruginosa possess the gene bla oxa 1 like gene from 40 isolates, 10(25\%) isolates positive bla oxal like gene showed 4 (40\%) from clinical isolates and $6(60 \%)$ from nosocomial (figures not shown).

From 10 positive isolates, 4 strains of clinical isolates; urine and ear isolates were multi-drug resistant. The prevalence of blaoxa-1 positive isolates of ESBL P. aeruginosa occurred in $40 \%$ of isolates and MDR phenotype was common in $P$. aeruginosa. The most prevalent gene among ESBL producers were blaOXA-1 which compromises the efficacy of MDR bacteria especially in clinical(urine, ear, and stool samples) and nosocomial samples (operation hall, burning gown, and ICU ) according to the results in this study and tend to be geographically limited.

The blaOXA-1 ESBLs provide $P$. aeruginosa with an additional powerful resistance mechanism with potentially serious clinical implications, including limitation of the therapeutic options. ESBLs manufacturing organisms create distinctive challenges to clinical microbiologists, clinicians, infection control professionals and scientists engaged in finding new antibacterial agents ${ }^{(19)}$. In this study, the prevalence of blaoxa-1 of $P$. aeruginosa isolates was $25 \%$ that less than values reported in different studies like in Iran; Malaysia; and Pakistan

This study reported 10 isolates (25\%) of blaOXA-1 ESBL of $P$. aeruginosa in clinical and nosocomial isolates from 40 isolates. The studies conducted by others depicted low rates, 7.7\% (J Jacoby GA) ${ }^{(20)}, 3.7 \%$ (Neil Woodford et al) ${ }^{(21)}, 4.2 \%$ (Lim et al., ${ }^{(22)}$ respectively, of ESBL production of $P$. aeruginosa.

Ethical Clearance: The Research Ethical Committee at scientific research by ethical approval of both environmental and health and higher education and scientific research ministries in Iraq

Conflict of Interest: The authors declare that they have no conflict of interest.

Funding: Self-funding

\section{References}

1. Gellatly, S. L., and Hancock, R. E. W. Pseudomonas aeruginosa: New insights into pathogenesis and host defenses. Pathogens and Disease, (2013). 67(3), 159-173.

2. Breed, R. S., Murray., E. G. D., \& Smith, N. R. Bergey's Manual of Systematic Bacteriology. Igarss 2014, (1), 1-5.

3. Bayat E.; Kamali M.; Zare'ei Mahmoodabdi A.; Mortazavi Y.; Ebrahim Habibi A.; Amini B.; Javadi H. R.; Farhadi N.; Haji Ojagh Faghihi MIsolation, determination and cloning of translocation domain of exotoxin A from Pseudomonas aeruginosa, Kowser Medical Journal .(2010).3:149-154. 
4. Vered Schechner; Vandack Nbre; Keith, S. Kaye; Moshe Leshno; Michael Giladi; Peter Rohner; Stephan Harbarth; Deverick, J. Anderson; Adolf, W. Karchmer; Mitchell, J. Schwaber, and Yehuda Carmeli Gram-negative bacteria upon hospital admission, when should Pseudomonas aeruginosa be suspected? J Country International Diseases (2009). (48).13-18

5. Brown, A., Horobin, A., Blount, D. G., Hill, P. J., English, J., Rich, A., and Pritchard, D. I. Blow fly Lucilia sericata nuclease digests DNA associated with wound slough/eschar and with Pseudomonas aeruginosa biofilm. Medical and veterinary entomology, (2012). 26(4), 432-439.

6. Miyata, S., Casey, M., Frank, D. W., Ausubel, F. M., and Drenkard, E. Use of the Galleria mellonella caterpillar as a model host to study the role of the type III secretion system in Pseudomonas aeruginosa pathogenesis. Infection and Immunity, (2003). 71(5), 2404-2413.

7. David R. H, Helena M. R. T. Parracho, James Walker, Richard S.G., Maria W., Susan L. and Sandra MBacteriophages and Biofilms Antibiotics, . (2014) : 3, 270-284.

8. Forbes, A.; Sahm, F. and Weissfeld, S. Bailey and Scott 's, Diagnostic Microbiology. International Twelfth Edition , (2007) pages 172,etc.

9. Zahra Tavajjohi, Rezvan Moniri and Ahmad Khorshidi, Detection and characterization of multidrug resistance and extended-spectrumbeta-lactamase-producing (ESBLS)Pseudomonas aeruginosa isolates in teaching hospital, Department of Biology, Faculty of Science, Alzahra University, Tehran, Iran, African Journal of Microbiology Research (2011). 5(20), : 3223-3228.

10. Moore, N.M. and Flaws, M.L. Antimicrobial resistance mechanisms in Pseudomonas aeruginosa. Clin Lab Sci; (2011). 24: 47-51.

11. Driscoll, J. A., Brody, S. L., \& Kollef, M. H. The Epidemiology, Pathogenesis and Treatment of Pseudomonas aeruginosa Infections.Vol. New Zealand: Adis. International. (2007). 67, 351-351.

12. Rowland and Belinda. Pseudomonas infections. The Gale Encyclopedia of Medicine. Second Edition. ( 2001).
13. Vandeale Simaey., Franckx, H., Verhelst, R., Schelstraete, P., Haerynck, F., L., Claeys, G., and De Baets, F. Epidemiology of Pseudomonas aeruginosa in a cystic fibrosis rehabilitation centre. European Respiratory Journal, (2005). 25(3), 474481.

14. Prinsloo, A.; Van Straten, A.M.S. and Weldhagen, G.F. Antibiotic synergy profiles of multi-drug resistant $P$. aeruginosa in a nosocomial environment. South Afr. J. Epidemiol. Infect.; (2008). 23(3): 7-9.

15. Malla, K.K.; Sarma, M.S.; Malla, T. and Thapalial.A. Clinical profile, bacterial isolates and antibiotic susceptibility patterns in urinary tract infection in children - hospital-based study. J. Nepal Paediatr. Soc.; ( 2008). 28(2):52-61.

16. Saegeman V., Huynen P., Colaert J., Melin P., and Verhaegen J. Susceptibility testing of Pseudomonas aeruginosa by the Vitek 2 system comparison with test results; Microbiology, Aspirant Researcher of the Fund for Scientific Research. (2010).

17. Osazuwa, F.; Nwofor, Q. and Ibeh, I.N. Aetiology agent of Otitis media in Benin City, Nigeria, Research Journal of Medical Science, ( 2011). 5, 112-115.

18. Nikibin VS., Abdi. A., Feizabadi MM and Gharavi S. Pulsed-field gel electrophoresis and plasmid profile of Pseudomonas aeruginosa at two hospitals in Tehran, Iran. Indian J Med. Res. (2007). 126: 146-151.

19. Hirsch EB, Impact of multidrug-resistant Pseudomonas aeruginosa infection on patient outcomes, Journal of Hospital Infection. (2010).: 34: $13-16$

20. Jacoby GA Extended-spectrum beta-lactamases and other enzymes providing resistance to oxyiminobeta-lactams. Infect. Dis. Clin. North. Am., (1997). 11: 875-887.

21. Woodford, N., and Johnson, A. P. (2004). Genomics, proteomics, and clinical bacteriology. Springer.

22. Lim KT, Yasin RM, Yeo CC, Puthucheary SD, Balan G, Maning N, Wahab ZA, Ismail N, Tan EA, Mustaffa A, Thong KL Genetic fingerprinting and antimicrobial susceptibility profiles of Pseudomonas aeroginosa hospital isolate in Malaysia. J. Microbiol. Immunol. Infect., .(2009). 42: 197-209. 